\title{
Growth and prevalence of feeding difficulties in children with Robin sequence: a retrospective cohort study
}

\author{
Emma C. Paes ${ }^{1}$ - Iris A.C. de Vries ${ }^{1}$ • Wouter M. Penris ${ }^{2}$ - Karlijn H. Hanny ${ }^{1}$ • \\ Selma W. Lavrijsen ${ }^{3}$ • Elselien K. van Leerdam ${ }^{1}$ - Maaike M. Rademaker ${ }^{1}$. \\ Esther S. Veldhoen ${ }^{3}$ - Rene M.J.C. Eijkemans ${ }^{4}$ - Moshe Kon ${ }^{1}$ • Corstiaan C. Breugem ${ }^{1,5}$
}

Received: 27 August 2015 / Accepted: 1 November 2016/Published online: 21 November 2016

(C) The Author(s) 2016. This article is published with open access at Springerlink.com

\begin{abstract}
Objectives In addition to breathing problems, patients with Robin sequence (RS) often encounter feeding difficulties (FD). Data regarding the occurrence of FD and possible influencing factors are scarce. The study aim was to elucidate these factors to improve treatment strategies.

Material and methods A retrospective comparative cohort study was conducted, consisting of 69 infants diagnosed with both RS and a cleft palate and 64 isolated cleft palate only (iCPO) infants. Data regarding FD, growth, and airway intervention were collected during the first 2 years of life. A systematic review of the literature was conducted to identify reported FD in RS patients.

Results RS patients had more FD (91\%) than iCPO patients (72\%; $p=0.004)$. Also, nasogastric (NG)-tube feeding was necessary more frequently and for a longer period (both $p<0.001)$. Growth was lower in RS than iCPO infants $(p=0.008)$ and was not affected by the kind of airway
\end{abstract}

Emma C. Paes and Iris A.C. de Vries contributed equally to this work.

Emma C. Paes

emmapaes@gmail.com

1 Department of Pediatric Plastic Surgery, Wilhelmina Children's Hospital, University Medical Centre, PO Box 85500, 3508, GA Utrecht, The Netherlands

2 Faculty of Behavioral and Social Sciences, University of Groningen, Groningen, The Netherlands

3 Department of Pediatrics, Wilhelmina Children's Hospital, Utrecht, The Netherlands

4 Department of Biostatistics and Research Support, Julius Centre, University Medical Centre, Utrecht, The Netherlands

5 Department of Plastic Surgery, Meander Medical Center, Amersfoort, The Netherlands management (conservative/surgical; $p=0.178$ ), cleft palate grade $(p=0.308)$, or associated disorders $(p=0.785)$. By contrast, surgical intervention subtype did significantly affect growth. Mean reported FD for RS in the literature is $80 \%$ $($ range $=47-100 \%)$, and $55 \%($ range $=11-100 \%)$ of infants need NG-tube feeding.

Conclusions FD is present in a large proportion of infants with RS, which indicates the need for early recognition and proper treatment to ensure optimal growth. Growth during the first 2 years of life is significantly lower in RS patients than iCPO patients, which indicates the need for careful attention and long-term follow-up.

Clinical relevance This study indicates the need for early recognition and proper treatment of FD in RS to ensure optimal growth. In addition, growth needs careful attention and longterm follow-up.

Keywords (Pierre) Robin sequence $\cdot$ Cleft palate . Treatment $\cdot$ Feeding difficulties $\cdot$ Growth $\cdot$ Weight . Systematic review

\section{Introduction}

Although preceded by several earlier reports [1,2], the French stomatologist Pierre Robin is credited as the first to draw attention to a symptom triad of breathing problems, glossoptosis, and micrognathia, known as Robin sequence (RS) [3, 4]. RS occurs in 1 in 8000 [5, 6] to 14,000 [7], depending on geography, ethnicity, and definition. Associated syndromes or anomalies coincide with RS in the majority of cases [8], and a concomitant cleft palate (CP) may exist but is not a required feature of RS [9-15].

Besides the varying degrees of respiratory problems, infants with RS frequently have feeding difficulties (FD) [16]. 
Swallowing difficulties directly related to the glossoptosis [16] and oroesophageal motor disorders caused by primary brainstem dysfunction [17] have been described as causes. FD is also a common feature in infants with a CP $[18,19]$. These physiological abnormalities impede successful coordination of breathing, sucking, and swallowing. In infants with $\mathrm{RS}$ and a concomitant $\mathrm{CP}$, these features can negatively affect the feeding process and there is a considerable risk of failure to thrive [20]. Consequently, these patients are often in need of nasogastric (NG)-tube feeding [21].

Although the majority of infants with RS and airway obstruction can be treated conservatively [22-26], surgical measures such as tongue lip adhesion (TLA) [27, 28], tracheotomy $[29,30]$, or mandibular distraction osteogenesis (MDO) [31-33] may be necessary. While the effect of these interventions on the obstructed airway has been frequently reported, information regarding the influence on FD is limited [16, 34].

To the best of our knowledge, this study is the first to identify factors that influence feeding and growth in RS and describe weight gain in the first 2 years of life. By obtaining a better understanding of all the facets of this condition, the treatment of these infants can be further optimized.

\section{Patients and methods}

\section{Retrospective cohort study}

\section{Baseline characteristics}

All infants diagnosed with RS (defined as the presence of micrognathia, glossoptosis, and signs of airway obstruction) and a concomitant CP treated at the Wilhelmina Children's Hospital Utrecht, the Netherlands between 1996 and 2012 were included in the study group. All infants diagnosed with an isolated $\mathrm{CP}$ only (iCPO), without associated anomalies, were included in the control group. A retrospective analysis of the medical records during the first 2 years of life was conducted. Ethics committee approval was obtained to conduct this study (reference number WAG/th/14/020120).

The following variables were extracted from the medical files: gender, gestational age (GA), birth weight, grade of CP (grade 1-4) [35], and airway and nutritional treatment. In the study group, a subdivision was made between non-isolated RS infants (i.e., diagnosis of an additional syndrome, associated anomalies, or chromosomal defects) and isolated RS infants. Airway intervention was either conservative (i.e., prone/ side positioning and possible use of supplemental oxygen, nasopharyngeal airway (NPA), oropharyngeal airway (mayotube), or continuous positive airway pressure) or surgical. The surgical intervention group was further divided into five subtypes: MDO, TLA, tracheotomy (Tr), TLA + Tr, and $\mathrm{MDO}+\mathrm{Tr}$.

\section{Feeding and growth}

FD were defined as (parentally) reported feeding problems, such as choking, regurgitation, gagging, distress, long-lasting feedings ( $\geq 30 \mathrm{~min}$ ), impaired intake, and/or nasal regurgitation [36]. FD can lead to insufficient weight gain, failure to thrive, need for NG-tube feeding, and can potentiate airway or respiratory compromise [14]. Medical records and growth charts were thoroughly analyzed. In addition, parents received a phone call requesting participation in a short questionnaire about FD.

The following variables were collected: presence of FD, need and duration of NG-tube feeding, and weight at birth and at 1, 3, 6, 9, 11, 14, 17, and 24 months of age (if available). Growth was measured as a change between the consecutive measurements at these nine time points. In addition, normal weight standard deviation scores of healthy controls were collected [37]. In the surgical intervention subtypes, besides total NG-tube duration, the postoperative (i.e., after the airway intervention) NG-tube duration was also collected.

\section{Statistical analysis}

Data were analyzed using SPSS 20.0 (IBM SPSS, NY, USA). For interactions between nominal variables, chi-squared tests were used. To compare interactions between nominal and interval variables, $t$ tests and one-way ANOVA were computed. For two interval variables, two-way Pearson correlations were calculated. To compare growth, linear mixed model analysis was performed to model the repeated measurements data. In non-normally distributed data, non-parametric tests were used: Mann-Whitney $U$ and Kruskal-Wallis $H$.

\section{Systematic literature review}

A systematic review of the literature was performed according to the Preferred Reporting Items for Systematic Reviews and Meta-Analysis (PRISMA) guidelines to assess current data on the combination of RS and FD [38]. Electronic databases were searched using specific keywords (Table 1) for articles published between July 1967 and August 2014, according to the search and inclusion processes as illustrated in Fig. 1. All relevant level I to level IV articles [39] were included for further analysis (Table 2).

\section{Results}

\section{Baseline characteristics}

Sixty-nine RS patients (study group) and 64 consecutive iCPO patients (control group) were included. The study group included significantly more patients with a grade $3 / 4 \mathrm{CP}$ than 
Table 1 Search strategy of the systematic literature reviews in the databases used

\begin{tabular}{|c|c|}
\hline Database & Search query \\
\hline PubMed & $\begin{array}{l}\text { (((“Pierre Robin Syndrome”[Mesh]) OR (pierre robin syndrome[tiab] OR pierre robin sequence[tiab] OR } \\
\text { PRS[tiab] OR pierre robin[tiab] OR robin sequence*[tiab]))) AND ((“"Feeding Behavior”[Mesh]) OR } \\
\text { "Eating Disorders"[Mesh]) OR (feeding behavior*[tiab] OR feeding behaviour*[tiab] OR feed*[tiab] } \\
\text { OR nutrition*[tiab] OR feeding difficult*[tiab] OR eating difficult*[tiab] OR feeding problem*[tiab] } \\
\text { OR eating problem*[tiab] OR eating disorder*[tiab])) }\end{array}$ \\
\hline Embase & 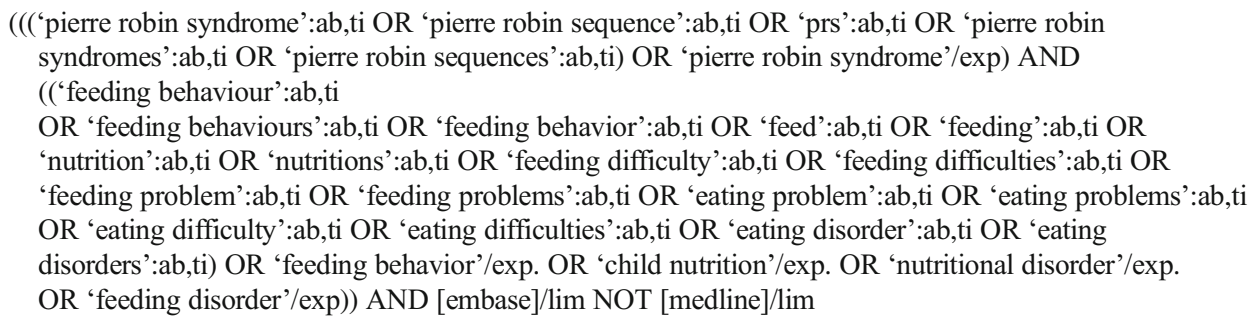 \\
\hline Cochrane library & $\begin{array}{l}\text { Feeding behaviour* OR feeding behavior* OR feed* OR nutrition* OR feeding difficult* OR eating } \\
\text { difficult* OR feeding problem* OR eating problem* OR eating disorder*:ti OR feeding behavior* } \\
\text { OR feeding behavior* OR feed* OR nutrition* OR feeding difficult* OR eating difficult* OR feeding } \\
\text { problem* OR eating problem* OR eating disorder*:ab AND pierre robin syndrome OR pierre robin } \\
\text { sequence OR PRS OR pierre robin OR robin sequence*:ti OR pierre robin syndrome OR pierre robin } \\
\text { sequence OR PRS OR pierre robin OR robin sequence*:ab }\end{array}$ \\
\hline CINAHL & $\begin{array}{l}\text { (TI pierre robin syndrome OR pierre robin sequence OR PRS OR pierre robin OR robin sequence* OR } \\
\text { AB pierre robin syndrome OR pierre robin sequence OR PRS OR pierre robin OR robin sequence*) } \\
\text { AND (S1 AND S2) } \\
\text { TI (pierre robin syndrome OR pierre robin sequence OR PRS OR pierre robin OR robin sequence*) OR } \\
\text { AB (pierre robin syndrome OR pierre robin sequence OR PRS OR pierre robin OR robin sequence*) } \\
\text { TI (Feeding behaviour* OR feeding behavior* OR feed* OR nutrition* OR feeding difficult* OR eating } \\
\text { difficult* OR feeding problem* OR eating problem* OR eating disorder) OR AB (Feeding behaviour* } \\
\text { OR feeding behavior* OR feed* OR nutrition* OR feeding difficult* OR eating difficult* OR feeding } \\
\text { problem* OR eating problem* OR eating disorder) }\end{array}$ \\
\hline Google Scholar & $\begin{array}{l}\text { pierre robin sequence OR pierre robin syndrome OR PRS AND feeding difficulties OR feeding problems } \\
\text { OR nutrition }\end{array}$ \\
\hline
\end{tabular}

CINAHL Cumulative Index to Nursing and Allied Health Literature

the control group $(p<0.001)$. The majority of the study group ( $54 \% ; n=37$ ) was made up of non-isolated RS patients. Of these, more than half had an associated syndrome (51\%, $n=19)$, Stickler syndrome ( $n=9)$ being the most common (Table 3).

\section{FD and NG-tube feeding}

RS patients expressed FD (91\%; $n=63)$ more than iCPO patients $(72 \% ; n=38, p=0.004)$. In RS and iCPO patients with $\mathrm{FD}$, a highly significant association was found in $\mathrm{CP}$ grade between the two groups $(p<0.001)$; while a grade 3 and $4 \mathrm{CP}$ was most common in RS patients with FD (grade $3=60 \%, n=37$; grade $4=23 \%, n=14$ ), a grade $2 \mathrm{CP}$ was most common in iCPO patients with FD (50\%; $n=19$; Table 4). In a logistic regression analysis controlled for $\mathrm{CP}$ grade, presence of FD was still significantly associated with the RS patient group $(p=0.005)$.

NG-tube feeding was more often necessary in RS patients $(80 \% ; n=55)$ than iCPO patients $(19 \% ; n=12, p<0.001)$.
Furthermore, NG-tube feeding lasted longer in RS patients (median 59.0 days in study group vs. median 9.6 days in control group, $p<0.001$ ). There was no significant association between the grade of CP (1-4) and the incidence of NG-tube feeding ( $p=0.23$; Table 4). NG-tube duration of the isolated (125 days; SD 203) and non-isolated (125 days; SD 171) RS patients did not differ significantly $(p=0.996)$.

\section{Growth}

Birth weights of the two groups were comparable (iCPO group $3302 \mathrm{~g}$ vs. RS group $3217 \mathrm{~g}, p=0.41$ ). However, the iCPO group showed a significantly higher overall growth over the time points 1-9 (birth to 24 months of age) than the RS group $(p=0.008)$. This increased growth in the iCPO group was also visible when separately analyzing time points $1-4$ (birth to 6 months of age) and 5-9 (9-24 months of age; Table 5 and Fig. 2). When additionally controlling for grade of CP over time points $1-9$, this difference remained significant $(p=0.030)$. 
Fig. 1 PRISMA flow diagram of the literature search

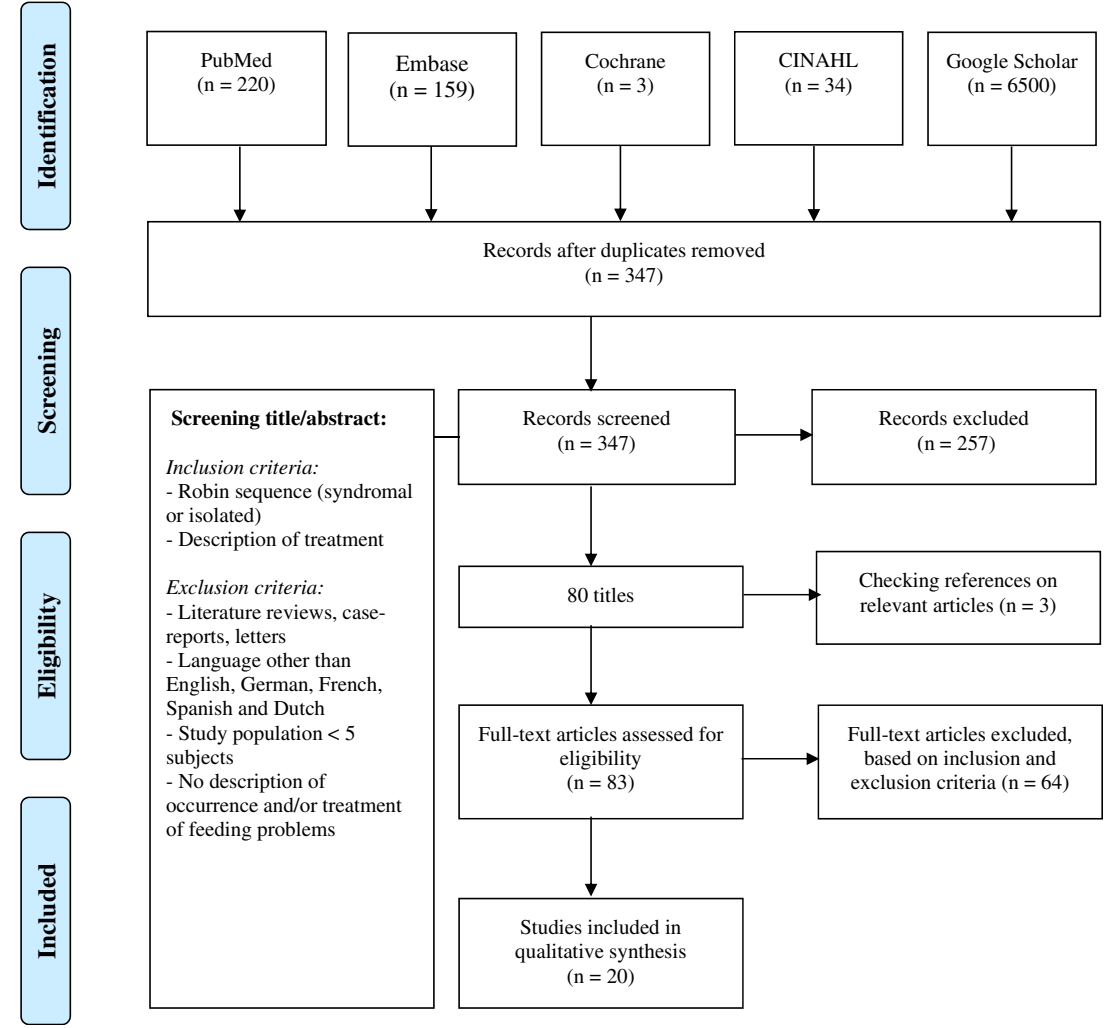

Taken into consideration all nine time points, in the following analysis, both gender and group (iCPO vs. RS) were controlled for. Neither presence of FD nor the need for NG-tube feeding revealed significant effects on growth $(p=0.893$ and $p=0.467$, respectively). Furthermore, the grade of CP (1-4) did not significantly affect growth $(p=0.308$; Table 5$)$. Since a clinical interaction between the CP grade and group type could exist, this was also separately tested, showing that the interaction between the grade of CP (1-4) and group did not significantly affect growth $(p=0.112)$.

Within the RS group, neither the presence of associated disorders (isolated/non-isolated) nor intervention type (surgi$\mathrm{cal} /$ conservative) had a significant effect on growth $(p=0.517$ and $p=0.052$, respectively; Table 5).

\section{Interventions in the study group}

While $40(60 \%)$ RS patients could be treated with conservative measures, in 27 infants (40\%), a surgical intervention was performed because of severe respiratory distress. MDO was pursued at a mean age of 36 days (SD 32) in 14 (52\%) of these cases, TLA (mean age $=77$ days, SD 49) in 3 cases (11\%), and a tracheotomy was performed (mean age $=45$, SD 27$)$ in 7 cases $(26 \%)$. Finally, in one case after TLA, a tracheotomy was performed due to an unstable airway. In two other cases, MDO was performed after tracheotomy (Table 6). Background information on the decisional process can be found in earlier work [55].
FD showed a significant association with intervention (surgical/conservative; $p=0.04$ ); while all surgically treated patients had FD $(100 \%)$, in the conservatively treated group $85 \%$ expressed FD. Since $100 \%$ of the surgically treated patients showed FD, further investigation of presence of FD within the type of surgical treatment was not possible (Table 6).

Surgically treated RS patients were significantly more often in need of NG-tube feeding than conservatively treated patients (93 vs. $63 \%, p=0.03$ ). NG-tube feeding lasted significantly longer in surgically treated RS patients (median $=72.0$ days; mean rank 29.4; $p=0.011$ ) compared to conservatively treated patients (median $=21.0$ days; mean rank 19.2). Surgical intervention subtype had a significant effect on postoperative duration of NG-tube feeding ( $p=0.003$, with a median of 36.5 days for MDO, 183.0 days for TLA, 461.5 days for Tr, and 38.0 days for MDO + Tr. A post hoc test revealed significant differences between all these group interactions $(p<0.05)$, except for TLA vs. Tr $(p=0.302)$, TLA vs. MDO $+\operatorname{Tr}(p=0.083)$, and MDO vs. $\mathrm{MDO}+\operatorname{Tr}(p=0.874$; Table 6).

The subtype of surgical intervention (MDO, TLA, Tr, TLA $+\mathrm{Tr}$, or $\mathrm{MDO}+\mathrm{Tr}$ ) also demonstrated a significant effect on growth from birth to 24 months of age $(p=0.007)$; a post hoc test showed significant differences between MDO vs. $\mathrm{Tr}$ $(p=0.008)$, TLA vs. $\operatorname{Tr}(p=0.012), \operatorname{Tr}$ vs. TLA $+\operatorname{Tr}$ $(p=0.004)$, TLA + Tr vs. MDO $(p=0.05)$, and TLA $+\operatorname{Tr}$ vs. $\mathrm{MDO}+\operatorname{Tr}(p=0.029 ;$ Table 5). 


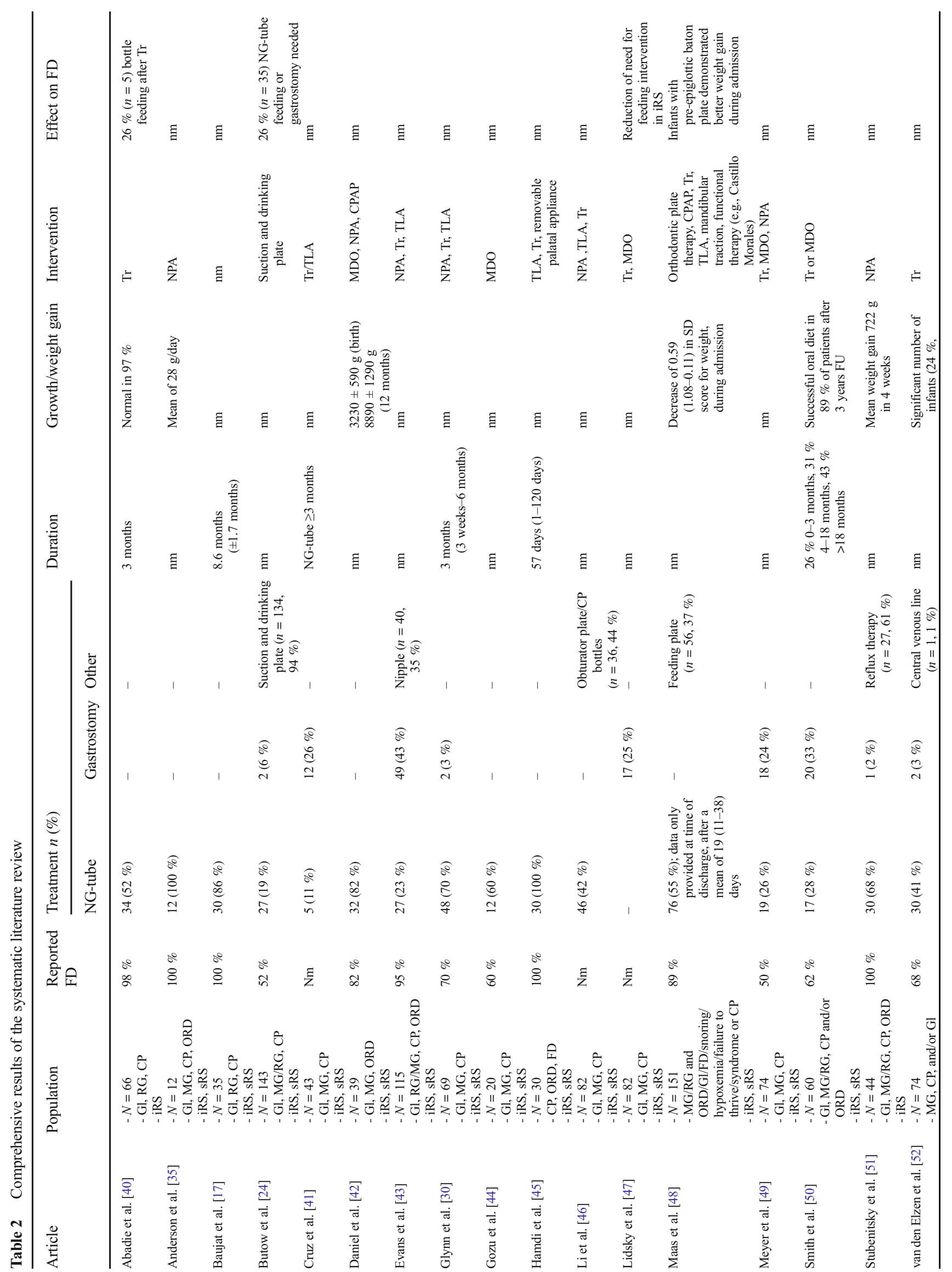




\section{Systematic literature review}

The literature search resulted in 347 unique titles. After initial screening, the full text of 80 potentially relevant articles was retrieved. References of these were checked, which provided three additional papers. These 83 texts were then analyzed by selection criteria and validity, yielding 20 articles (Table 2) [5, 17, 24, 30, 35, 40-54].

The selected reports included a mean of 65 patients (range $=22$ [54]-151 [48]) with mixed isolated and non-isolated RS cases. In the majority, RS was defined as infants expressing micrognathia, glossoptosis, and a $\mathrm{CP}$, while in the others, obstructive respiratory distress or FD were (optionally) included in the features of RS. An average of $80 \%$ of cases expressed FD (range $=47$ [53]-100 [17, 35, 45, 51] \%). On average, NG-tube feeding was given to $55 \%$ of the infants (range $=11$ [41]-100 [35, 45, 54] \%), and a gastrostomy in $17 \%$ (range $=2[24]-43[43] \%)$. Other feeding interventions described were special oral plates [24, 46, 48] or functional therapy (such as Castillo Morales) [5]. When mentioned, mean duration of NG-tube feeding varied between several weeks [30,54] and 18 months [50].

\section{Discussion}

\section{Feeding difficulties and growth}

FD are an important and common symptom in RS, possibly leading to failure to thrive and developmental problems, if not recognized and treated in time [40]. Up to $73 \%$ of infants with a CP have been reported to suffer FD [56]. The current study demonstrated that more FD were seen in infants with RS (91\%) than iCPO (72\%), also after controlling for CP grade $(p=0.005)$. All RS patients demonstrated a significantly lower growth than iCPO patients during the first 2 years of life irrespective of the treatment regime $(p=0.030)$ yet remained within the 0 SD (P50) and -1 SD (P16) line (Fig. 2). This finding is in line with other studies that have also demonstrated a lower birth weight in RS patients, compared to healthy individuals and iCPO patients [48, 52, 57, 58]. A hypothesis for the lower growth in RS infants is the presence of morphological characteristics as primary predisposing factors, which is supported by the finding that infants with CP have a tendency towards smaller cranial circumference [55]. Also genetic factors are of interest, especially the role of growth factors that might influence growth retardation in RS [57]. In addition, airway infections during 0-3 months of age negatively affect growth [59]. Finally, arguments for other origins of feeding disorders and subsequent growth retardation in patients with RS exist, such as primary brainstem dysfunction, or neuromotor disabilities, which might be more prevalent in 
Table 3 Baseline characteristics of the patients in the study and control groups treated in the Wilhelmina Children's Hospital between 1996 and 2012

\begin{tabular}{|c|c|c|c|c|}
\hline \multicolumn{2}{|l|}{ Variable } & \multirow{2}{*}{$\begin{array}{l}\text { Study group } \\
\text { (RS) } n(\%)\end{array}$} & \multirow{2}{*}{$\begin{array}{l}\text { Control group } \\
(\mathrm{iCPO}) n(\%)\end{array}$} & \multirow[t]{2}{*}{$p$ value* } \\
\hline Total number of patients & & & & \\
\hline \multirow[t]{2}{*}{ Sex } & Male & $32(46 \%)$ & $23(36 \%)$ & \multirow[t]{2}{*}{0.22} \\
\hline & Female & $37(54 \%)$ & $41(64 \%)$ & \\
\hline \multirow[t]{2}{*}{ Gestational age } & $<37$ weeks & $8(12 \%)$ & $7(11 \%)$ & \multirow[t]{2}{*}{0.91} \\
\hline & $\geq 37$ weeks & $61(88 \%)$ & $57(89 \%)$ & \\
\hline \multicolumn{2}{|l|}{ Birth weight (g) } & $\begin{array}{l}\text { Mean }=3217 \\
\mathrm{SD}=669\end{array}$ & $\begin{array}{l}\text { Mean }=3302 \\
\mathrm{SD}=556\end{array}$ & 0.44 \\
\hline \multirow[t]{4}{*}{ Grade of $\mathrm{CP}^{\mathrm{a}}$} & 1. Submucous cleft or bifid uvula & $3(4 \%)$ & $9(14 \%)$ & \multirow[t]{4}{*}{$<0.001$} \\
\hline & 2. Soft palate only & $10(15 \%)$ & $27(42 \%)$ & \\
\hline & 3. Soft palate and segment of hard palate & $38(56 \%)$ & $18(28 \%)$ & \\
\hline & 4. Total palate up to incisive foramen & $17(25 \%)$ & $10(16 \%)$ & \\
\hline \multirow[t]{13}{*}{ Associated disorders } & Isolated RS $32(46 \%)$ & & & \multirow[t]{13}{*}{0.06} \\
\hline & Non-isolated RS 37 (54 \%) & & & \\
\hline & Stickler syndrome & 9 & & \\
\hline & Treacher Collins syndrome & 2 & & \\
\hline & Spondyloepiphyseal dysplasia & 1 & & \\
\hline & $4 \mathrm{q}$ deletion syndrome & 1 & & \\
\hline & Van der Woude syndrome & 1 & & \\
\hline & Osteopathia striata with cranial sclerosis & 1 & & \\
\hline & Goldberg-Shprintzen syndrome & 1 & & \\
\hline & Yunis-Varon syndrome & 1 & & \\
\hline & Auriculo-condylar syndrome & 1 & & \\
\hline & Hemifacial microsomia & 1 & & \\
\hline & Other & 18 & & \\
\hline
\end{tabular}

$R S$ Robin sequence, $i C P O$ isolated cleft palate only, $S D$ standard deviation, $C P$ cleft palate

* $p$ value $<0.05$ was considered statistically significant

${ }^{a}$ Modified from Jensen et al. cleft palate classification (1988) [34], according to the division made in the Dutch Cleft Registry database

RS than iCPO patients $[17,40]$. Although CP patients have a lower weight than healthy controls [57], they tend to "catchup" later in childhood [57,59]. To date, no studies exist that describe growth patterns in patients with RS during a longer period. There is sparse evidence that severe functional feeding and respiratory disorders do not affect long-term developmental outcomes in infants with isolated RS of Stickler [21]. Still, longer follow-up studies of both isolated and non-isolated RS infant are needed to evaluate the cause, a possible catch-up in growth, and the effect of the lower weight on further (cognitive) development.

\section{Airway interventions}

Growth was not affected by the type of airway intervention (conservative vs. surgical, $p=0.178$ ); therefore, we hypothesize that adequate relief of airway obstruction is important to maintain adequate growth [60]. This finding is substantiated by similar findings of Daniel et al. [42], in which the degree of adequately treated OSA did not influence growth infants with RS. In the majority (58\%) of RS cases of our cohort, airway problems could be managed conservatively. Surgical options were only considered after NPA treatment failed [61]. Until 2006, either TLA or tracheotomy was performed. MDO has become our surgical procedure of preference in a supraglottic airway obstruction since 2006 [31, 61]. NG-tube feeding duration was significantly reduced after MDO treatment compared to the other surgical interventions, which corresponds with the results of others [34]. Lidksy and coauthors [47] show that also timing of surgery (i.e., MDO within 3 months) dramatically reduces the need for feeding interventions in isolated RS patients. Moreover, disappearance of gastroesophageal reflux has been demonstrated after MDO [16]. The positive effect of MDO on feeding capacity and growth has also been confirmed by others [44, 47, 62-64]. Interestingly, the RS infants of our cohort that received a tracheotomy had a significantly higher weight than the MDO or TLA group. This growth difference might result from a disproportionate presence 
Table 4 Association of feeding difficulties and NG-tube feeding between the study and the control groups

\begin{tabular}{|c|c|c|c|c|}
\hline \multicolumn{2}{|l|}{ Variable } & Study group (RS) & Control group (iCPO) & $p$ value* \\
\hline \multicolumn{2}{|c|}{ Total number of patients } & 69 & 64 & \\
\hline \multicolumn{2}{|c|}{ With feeding difficulties } & $63(91 \%)$ & $38(72 \%)$ & 0.004 \\
\hline \multirow[t]{2}{*}{ Sex } & Male & $27(43 \%)$ & $15(40 \%)$ & 0.74 \\
\hline & Female & $36(57 \%)$ & $23(61 \%)$ & \\
\hline \multirow[t]{2}{*}{ Gestational age } & $<37$ weeks & $7(11 \%)$ & $5(13 \%)$ & 0.76 \\
\hline & $\geq 37$ weeks & $56(89 \%)$ & $33(87 \%)$ & \\
\hline \multicolumn{2}{|l|}{ Birth weight (g) } & $\begin{array}{l}\text { Mean }=3237 \\
\mathrm{SD}=644\end{array}$ & $\begin{array}{l}\text { Mean }=3289 \\
\mathrm{SD}=586\end{array}$ & 0.68 \\
\hline \multirow[t]{4}{*}{ Grade of CP } & 1. Submucous cleft or bifid uvula & $2(3 \%)$ & $3(8 \%)$ & $<0.001$ \\
\hline & 2. Soft palate only & $9(15 \%)$ & $19(50 \%)$ & \\
\hline & 3. Soft palate and segment of hard palate & $37(60 \%)$ & $10(26 \%)$ & \\
\hline & 4. Total palate up to incisive foramen & $14(23 \%)$ & $6(16 \%)$ & \\
\hline \multirow[t]{2}{*}{ Associated disorders } & Non-isolated $\mathrm{RS}^{\mathrm{b}}$ & $36(57 \%)$ & NA & NA \\
\hline & Isolated RS & $27(43 \%)$ & & \\
\hline \multicolumn{2}{|l|}{ With NG-tube feeding } & $55(80 \%)$ & $12(19 \%)$ & $<0.001$ \\
\hline \multicolumn{2}{|c|}{ NG-tube feeding duration (days) } & $\begin{array}{l}\text { Median }=59.00 \\
\text { Mean rank }=33.13\end{array}$ & $\begin{array}{l}\text { Median }=9.56 \\
\text { Mean rank }=9.72\end{array}$ & $<0.001$ \\
\hline \multirow[t]{2}{*}{ Sex } & Male & $24(44 \%)$ & $7(58 \%)$ & 0.36 \\
\hline & Female & $31(56 \%)$ & $5(42 \%)$ & \\
\hline \multirow[t]{2}{*}{ Gestational age } & $<37$ weeks & $7(13 \%)$ & $4(33 \%)$ & 0.08 \\
\hline & $\geq 37$ weeks & $48(87 \%)$ & $8(67 \%)$ & \\
\hline \multicolumn{2}{|l|}{ Birth weight (g) } & $\begin{array}{l}\text { Mean }=3217 \\
\mathrm{SD}=661\end{array}$ & $\begin{array}{l}\text { Mean }=3039 \\
\mathrm{SD}=733\end{array}$ & 0.41 \\
\hline \multirow[t]{4}{*}{ Grade of $\mathrm{CP}^{\mathrm{a}}$} & 1. Submucous cleft or bifid uvula & $1(2 \%)$ & $0(0 \%)$ & 0.23 \\
\hline & 2. Soft palate only & $9(17 \%)$ & $5(42 \%)$ & \\
\hline & 3. Soft palate and segment of hard palate & $32(59 \%)$ & $4(33 \%)$ & \\
\hline & 4. Total palate up to incisive foramen & $12(22 \%)$ & $3(25 \%)$ & \\
\hline \multirow[t]{2}{*}{ Associated disorders } & Non-isolated $\mathrm{RS}^{\mathrm{b}}$ & $32(58 \%)$ & NA & NA \\
\hline & Isolated RS & $16(42 \%)$ & & \\
\hline
\end{tabular}

Due to missing values, the results for certain variables presented in this table do not correspond with the total participants per investigated variable $R S$ Robin sequence, $i C P O$ isolated cleft palate only, $S D$ standard deviation, $N G$-tube nasogastric tube, $N A$ not applicable $* p$ value $<0.05$ was considered statistically significant

${ }^{\text {a }}$ Modified from Jensen et al. cleft palate classification (1988) [34], according to the division made in the Dutch Cleft Registry database

${ }^{\mathrm{b}}$ Presence of a syndrome or other associated anomalies or chromosomal defects

of comorbidities or syndromes in the various surgical subtype groups, differing ages at surgery, or longer NGtube durations in infants treated with tracheotomy. Also the radical resolution of their obstruction might add to a longer stay under medical control and nutritional support. Data of a recent German review demonstrates that improvement of weight is also possible by the appliance of a pre-epiglottic baton plate (PEBP) in RS infants with severe upper airway obstruction [48, 65]. Treatment with this orthodontic appliance was associated with a higher increase of weight than infants treated with prone positioning or tracheotomy [48]. Moreover, at discharge, a decrease in the proportion of infants requiring NG-tube feeding from 66 to $8 \%$ was seen after PEBP treatment
[65]. Although we have no experience with this conservative treatment method, the results of others are very promising and could be considered in an institutional algorithm.

\section{Associated anomalies}

Infants with syndromes, such as in non-isolated RS, often express FD [66]. In the current study, a higher, although nonsignificant, presence of FD and NG-tube feeding frequency was seen in the non-isolated RS patients, compared with the isolated RS group. No significant effect of the presence of an associated disorder or syndrome was illustrated on growth, a finding that is in agreement with 
Table 5 Variable effects on growth measured by weight (in grams) over the nine measured time points

\begin{tabular}{|c|c|c|c|c|c|}
\hline \multicolumn{2}{|l|}{ Variable effects on growth ${ }^{\mathrm{a}}$} & \multirow{2}{*}{$\begin{array}{l}\text { EMM }(\mathrm{g}) \\
5620\end{array}$} & \multirow{2}{*}{$\begin{array}{l}\text { SE } \\
96\end{array}$} & \multirow{2}{*}{$\begin{array}{l}\begin{array}{l}95 \% \mathrm{CI} \\
\text { (upper bound-lower bound) }\end{array} \\
5263-5678\end{array}$} & \multirow{2}{*}{$\begin{array}{l}p \text { value* } \\
0.008\end{array}$} \\
\hline Time points $1-9$ (birth to 24 months of age) & $\mathrm{iCPO}$ & & & & \\
\hline & $\mathrm{RS}$ & 5261 & 95 & $5240-5581$ & \\
\hline \multirow[t]{2}{*}{ Time points $1-4$ (birth to 6 months of age) } & $\mathrm{iCPO}$ & 3805 & 65 & $3676-3934$ & 0.044 \\
\hline & $\mathrm{RS}$ & 3619 & 65 & $3471-3746$ & \\
\hline \multirow[t]{2}{*}{ Time points 5-9 (9 to 24 months of age } & $\mathrm{iCPO}$ & 9833 & 143 & $9551-10,114$ & 0.026 \\
\hline & RS & 9390 & 138 & $9119-9661$ & \\
\hline \multirow[t]{2}{*}{ Time points $1-9^{\mathrm{b}}$ (birth to 24 months of age) } & $\mathrm{iCPO}$ & 5588 & 106 & $5380-5796$ & 0.030 \\
\hline & RS & 5268 & 112 & $5047-5490$ & 5268 \\
\hline \multirow[t]{2}{*}{ Feeding difficulties ${ }^{\mathrm{c}, \mathrm{f}}$} & Yes & 6902 & 87 & $6147-6488$ & 0.467 \\
\hline & No & 6767 & 192 & $6094-6849$ & \\
\hline \multirow[t]{2}{*}{ NG-tube feeding ${ }^{\mathrm{c}, \mathrm{f}}$} & Yes & 6584 & 189 & $-396-346$ & 0.893 \\
\hline & No & 6559 & 189 & $-346-396$ & \\
\hline \multirow[t]{4}{*}{ Grade of $\mathrm{CP}^{\mathrm{c}, \mathrm{f}}$} & 1. Submucous cleft or bifid uvula & 5468 & 237 & $5019-5953$ & 0.308 \\
\hline & 2. Soft palate only & 5540 & 130 & $5283-5797$ & \\
\hline & 3. Soft palate and segment of hard palate & 5489 & 107 & $5278-5699$ & \\
\hline & 4. Total palate up to incisive foramen & 5198 & 146 & $4911-5486$ & \\
\hline \multirow[t]{2}{*}{ Associated disorders $\mathrm{d}, \mathrm{f}$} & Isolated RS & 6479 & 151 & $6181-6777$ & 0.517 \\
\hline & Non-isolated $\mathrm{RS}^{\mathrm{e}}$ & 6621 & 154 & $6317-6825$ & \\
\hline \multirow[t]{2}{*}{ Intervention type $\mathrm{d}^{\mathrm{f}} \mathrm{f}$} & Surgical & 6902 & 203 & $6504-7301$ & 0.052 \\
\hline & Conservative & 6484 & 179 & $6132-6836$ & \\
\hline \multirow[t]{5}{*}{ Surgical intervention subtype $\mathrm{d}^{\mathrm{d} f}$} & MDO & 7965 & 188 & $7587-8344$ & 0.007 \\
\hline & TLA & 7720 & 336 & $7049-8391$ & \\
\hline & $\operatorname{Tr}$ & 8765 & 223 & $8317-9213$ & \\
\hline & $\mathrm{TLA}+\mathrm{Tr}$ & 6423 & 752 & $4920-7927$ & \\
\hline & $\mathrm{MDO}+\mathrm{Tr}$ & 8383 & 412 & $7555-9210$ & \\
\hline
\end{tabular}

Time points: weight at birth, 1, 3, 6, 9, 11, 14, 17, and 24 months of age

$E M M$ estimated marginal means, $S E$ standard error, $C I$ confidence interval, $M D O$ mandibular distraction osteogenesis, TLA tongue lip adhesion, $T r$ tracheotomy, $N G$-tube nasogastric tube, $R S$ Robin sequence, $i C P O$ isolated cleft palate only, $C P$ cleft palate

$* p$ value $<0.05$ was considered statistically significant

${ }^{a}$ All measurements were controlled for gender

${ }^{\mathrm{b}}$ Also controlled for grade of CP

${ }^{\mathrm{c}}$ Also controlled for group

${ }^{\mathrm{d}}$ Only analyzed within the RS group

${ }^{\mathrm{e}}$ Presence of a syndrome or other associated anomalies or chromosomal defects

${ }^{\mathrm{f}}$ For time points $1-9$ (birth to 24 months of age)

other studies $[24,42,52,67,68]$. In addition, the duration of NG-tube feeding in isolated vs. syndromic RS patients was not different. However, other underlying problems (e.g., neuromotor dysfunction) might persist longer, having a negative effect on feeding capacity despite adequate relief of airway problems [17, 47, 52]. In some studies, a higher rate of gastrostomy placement has been found in syndromic than isolated RS patients [41, 69]. In conclusion, we suggest that infants with a syndromic diagnosis need closer follow-up to monitor growth and feeding capacity [70].

\section{Analysis and treatment of FD}

It is important to distinguish between respiratory-related FD and neuromotor disabilities that affect sucking and swallowing coordination [42, 71, 72]. Although numerous papers mention FD, there is still no scientific agreement about what they exactly encompass [36]. Consequently, these difficulties are regularly manifested in objectified measures, such as weight or the incidence of NG-tube feeding [36]. Also, several symptoms are proposed to confirm the presence of FD, such as dysphagia or gastroesophageal reflux (GER) 


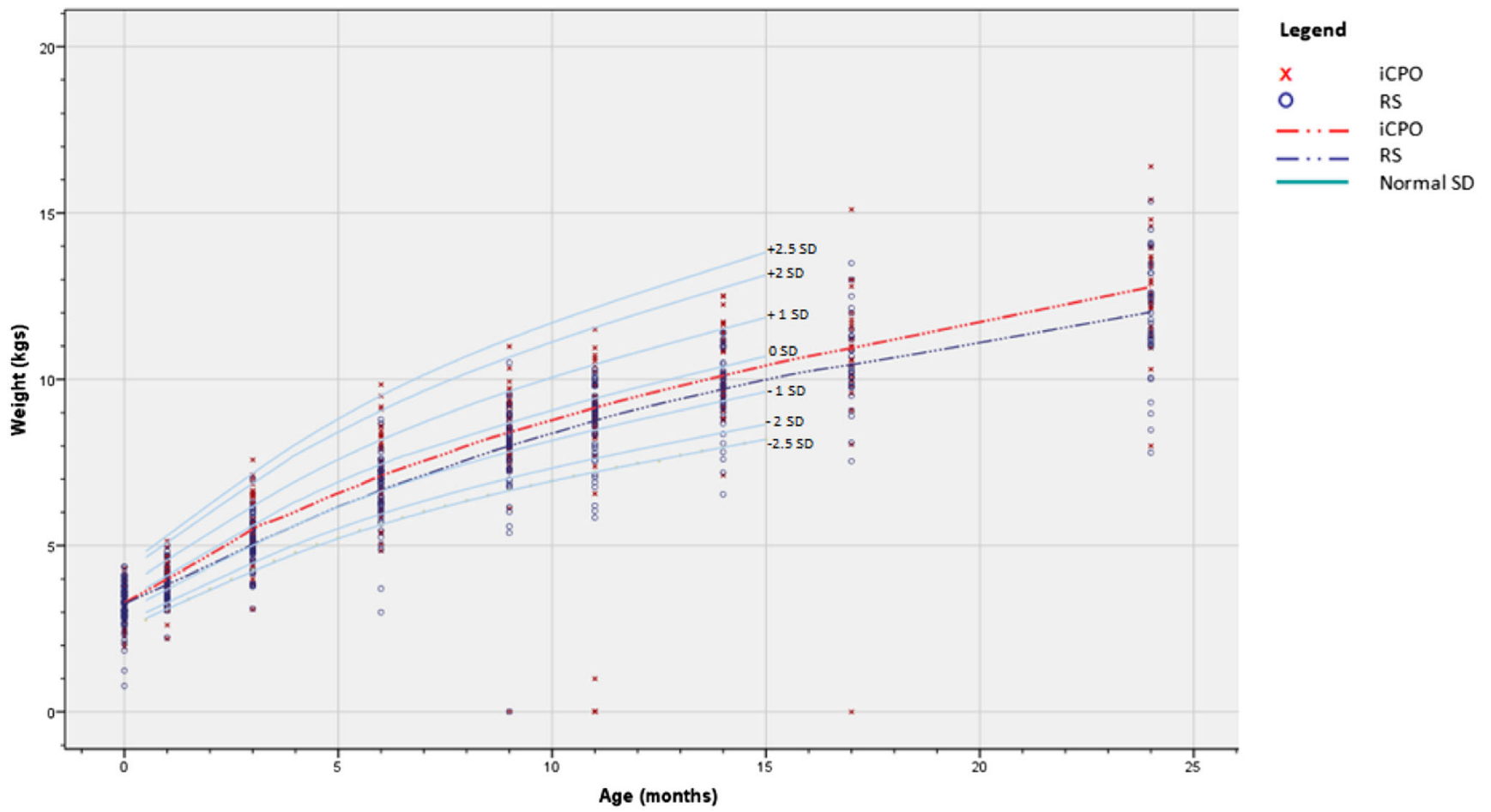

Fig. 2 Growth in the first 2 years of life in the study and control group, compared with normal SD values of healthy Dutch infants [37]

$[17,40,73-75]$. There is no consensus about which investigations should be performed, and their validity is sometimes questionable [75]. We strongly believe it is important to define feeding issues together with parents, feeding therapists, and pediatricians as early as possible. NG-tube feeding should be started when there is insufficient weight gain [14]. In our institution, infants with FD were more likely to receive NGtube feeding. When NG-tube feeding was adequately started, no differences in growth were seen between infants with reported FD and those without FD. The high frequency of FD in the iCPO group ( $72 \%$ ) contrasting with the low frequency of tube feeding in this group $(12 \%)$ is surprising. An explanation might be the parents' interpretation of the presence of FD, which does not correspond to the criteria of pediatricians to start with NG-tube feeding. This finding might emphasize that the parental concerns need to be addressed and discussed by the medical team during the treatment of an infant with an iCPO. If GER is clinically suspected, a trial of reflux therapy is started, as the incidence of GER is known to be higher in RS [30]. Marquis et al. [76] stress the importance of hypercaloric feeding and demonstrate a quicker improvement in weight gain and relief of respiratory problems, compared with controls. In addition, many authors advise feeding-facilitating techniques, by stimulating the orofacial and tongue musculature and encouraging sucking to improve neuromuscular coordination by introducing small amounts of bottle feeding $[5$, $30,54,77]$. Monitoring of urinary sodium has been suggested, as oral sodium supplementation in cases with a low urine sodium significantly improved weight gain in infants with RS [78]. Besides growth, maternal bonding [79], psychological well-being [80], and social and cognitive development $[18,19,81]$ can be negatively influenced by FD and need to be monitored during follow-up.

\section{Strengths and limitations}

The first limitation is the study's retrospective nature. We did not examine nutritional status by using other anthropometric measurements, such as mid upper arm circumference and skin fold thickness $[82,83]$. FD remains difficult to define and in addition to objective information retrieved from medical charts and growth charts we also included subjective information from parents. Consequently, differences in presence and severity of FD amongst the included infants existed and might also have been influenced by recall-bias. Other forms of promising therapy not used in our institution, such as Castillo Morales [5] or palatal plate therapy [45, 65, 84-87], have been described. Moreover, in our clinic, it is uncommon to perform a gastrostomy in children under 1 year of age; hence, we only provide data on usage of NG-tube. Finally, RS is a heterogenic disorder; thus, the distribution of syndromes or associated anomalies might influence the results. Strengths include that this is the first comparative study to report in detail on feeding issues and growth in two large cohorts over a 2-year study period, using weight at nine measuring moments as objective parameters and analyzing the influence of various parameters. 


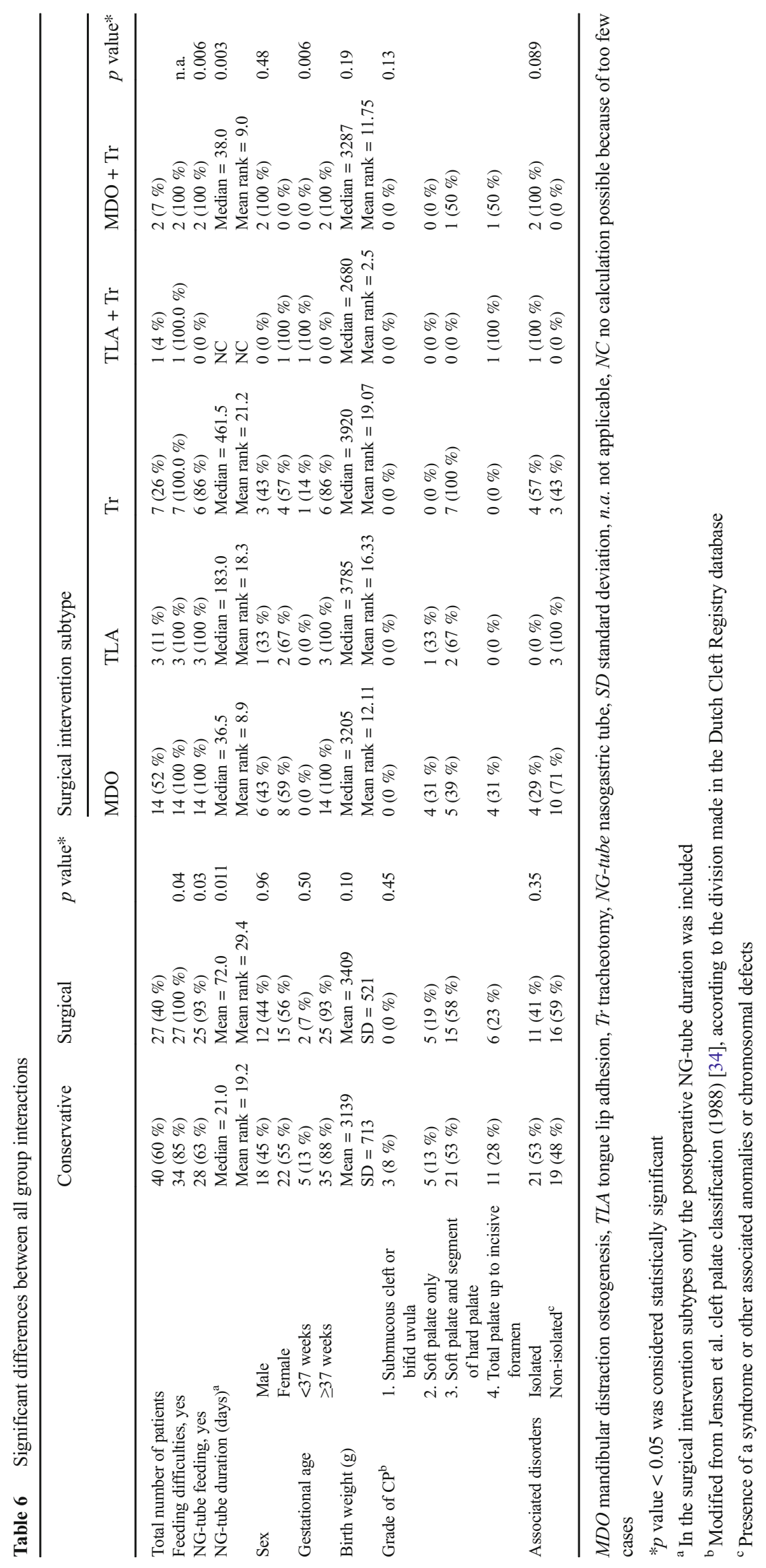




\section{Conclusion}

In this retrospective study, the prevalence of FD was significantly higher and NG-tube feeding was more frequent and for a longer period in infants with RS than iCPO. Growth in the first 2 years of life was significantly lower in RS than iCPO infants, although following a steady curve between the 0 and -1 SD line compared with healthy counterparts. Neither presence of associated syndromes nor the type of intervention negatively affected growth, which might be explained by early recognition and treatment of FD in our cohort. The subtypes of surgical intervention did reveal a significant effect on growth, which might be caused by the heterogeneity of the treated infants. The cause of the lower growth in RS infants and the long-term effects, despite an apparent good treatment regime in terms of airway relief and monitoring of the intake, mandates further investigation. By gaining insight about this challenging patient group, treatment strategies can be optimized and expectations of caretakers and parents better managed.

\section{Compliance with ethical standards}

Conflict of interest All authors declare that they have no conflict of interest.

Funding Miss Iris A.C. de Vries is PhD student and is partly funded by NutsOhra.

Ethical approval All procedures performed were in accordance with the ethical standards of the institutional and/or national research committee and with the 1964 Helsinki Declaration and its later amendments or comparable ethical standards.

Informed consent Informed consent was obtained from all individual participants included in the study.

Financial disclosure statement All authors state they have no financial relationships relevant to this article to disclose.

Open Access This article is distributed under the terms of the Creative Commons Attribution 4.0 International License (http:// creativecommons.org/licenses/by/4.0/), which permits unrestricted use, distribution, and reproduction in any medium, provided you give appropriate credit to the original author(s) and the source, provide a link to the Creative Commons license, and indicate if changes were made.

\section{References}

1. Fairburn $P$ (1846) Suffocation in an infant from retraction of the base of the tongue, connected with a defect in the frenum. Month $\mathrm{J}$ Med Sci 6:280-281

2. Shukowsky W (1911) Zur aetiologie des stridor inspiratorius congenitus. Jahrb Kinderheilk 73:459-474

3. Robin P (1934) Glossoptosis due to atresia and hypotrophy of the mandible. Am J Dis Child 48:541-547
4. Robin P (1923) La chute de la base de la langue considérée comme une nouvelle cause de gans la respiration naso-pharyngienne. Bull Acad Natl Med 89:37-41

5. Vatlach S, Maas C, Poets CF (2014) Birth prevalence and initial treatment of Robin sequence in Germany: a prospective epidemiologic study. Orphanet J Rare Dis 9:9

6. Bush PG, Williams AJ (1983) Incidence of the Robin Anomalad (Pierre Robin syndrome). Br J Plast Surg 36:434

7. Printzlau A, Andersen M (2004) Pierre Robin sequence in Denmark: a retrospective population-based epidemiological study. Cleft Palate Craniofac J 41:47

8. Izumi K, Konczal LL, Mitchell AL et al (2012) Underlying genetic diagnosis of Pierre Robin sequence: retrospective chart review at two children's hospitals and a systematic literature review. J Pediatr 160:645

9. Amaratunga NA (1989) A comparative clinical study of Pierre Robin syndrome and isolated cleft palate. Br J Oral Maxillofac Surg 27:451

10. Breugem CC, Courtemanche DJ (2010) Robin sequence: clearing nosologic confusion. Cleft Palate Craniofac J 47:197

11. Caouette-Laberge L, Bayet B, Larocque Y (1994) The Pierre Robin sequence: review of 125 cases and evolution of treatment modalities. Plast Reconstr Surg 93:934

12. Mackay DR (2011) Controversies in the diagnosis and management of the Robin sequence. J Craniomaxillofac Surg 22:415

13. Rintala A, Ranta R, Stegars T (1984) On the pathogenesis of cleft palate in the Pierre Robin syndrome. Scand J Plast Reconstr Surg $18: 237$

14. Schaefer RB, Gosain AK (2003) Airway management in patients with isolated Pierre Robin sequence during the first year of life. J Craniomaxillofac Surg 14:462

15. Schaefer RB, Stadler JA III, Gosain AK (2004) To distract or not to distract: an algorithm for airway management in isolated Pierre Robin sequence. Plast Reconstr Surg 113:1113

16. Monasterio FO, Molina F, Berlanga F et al (2004) Swallowing disorders in Pierre Robin sequence: its correction by distraction. J Craniomaxillofac Surg 15:934

17. Baujat G, Faure C, Zaouche A et al (2001) Oroesophageal motor disorders in Pierre Robin syndrome. J Pediatr Gastroenterol Nutr 32:297

18. Neiman GS, Savage HE (1997) Development of infants and toddlers with clefts from birth to three years of age. Cleft Palate Craniofac J 34:218

19. Jocelyn LJ, Penko MA, Rode HL (1996) Cognition, communication, and hearing in young children with cleft lip and palate and in control children: a longitudinal study. Pediatrics 97:529

20. Reid J, Kilpatrick N, Reilly S (2006) A prospective, longitudinal study of feeding skills in a cohort of babies with cleft conditions. Cleft Palate Craniofac J 43:702

21. Thouvenin B, Djadi-Prat J, Chalouhi C et al (2013) Developmental outcome in Pierre Robin sequence: a longitudinal and prospective study of a consecutive series of severe phenotypes. Am J Med Genet A 161A:312

22. Abel F, Bajaj Y, Wyatt M et al (2012) The successful use of the nasopharyngeal airway in Pierre Robin sequence: an 11-year experience. Arch Dis Child 97:331

23. Bacher M, Sautermeister J, Urschitz MS et al (2011) An oral appliance with velar extension for treatment of obstructive sleep apnea in infants with pierre robin sequence. Cleft Palate Craniofac J 48:331

24. Butow KW, Hoogendijk CF, Zwahlen RA (2009) Pierre Robin sequence: appearances and 25 years of experience with an innovative treatment protocol. J Pediatr Surg 44:2112

25. de Buys Roessingh AS, Herzog G, Hohlfeld J (2007) Respiratory distress in Pierre Robin: successful use of pharyngeal tube. J Pediatr Surg 42:1495 
26. Mondini CC, Marques IL, Fontes CM et al (2009) Nasopharyngeal intubation in Robin sequence: technique and management. Cleft Palate Craniofac J 46:258

27. Mokal NJ, Desai MF, Sawant P (2013) Reinventing the technique of tongue-lip adhesion in Pierre Robin sequence. J Plast Reconstr Aesthet Surg .

28. Bijnen CL, Don Griot PJ, Mulder WJ et al (2009) Tongue-lip adhesion in the treatment of Pierre Robin sequence. J Craniomaxillofac Surg 20:315

29. Benjamin B, Walker P (1991) Management of airway obstruction in the Pierre Robin sequence. Int J Pediatr Otorhinolaryngol 22:29

30. Glynn F, Fitzgerald D, Earley MJ et al (2011) Pierre Robin sequence: an institutional experience in the multidisciplinary management of airway, feeding and serous otitis media challenges. Int $\mathrm{J}$ Pediatr Otorhinolaryngol 75:1152

31. Breugem C, Paes E, Kon M et al (2012) Bioresorbable distraction device for the treatment of airway problems for infants with Robin sequence. Clin Oral Investig 16:1325-1331

32. Burstein FD (2008) Resorbable distraction of the mandible: technical evolution and clinical experience. J Craniomaxillofac Surg 19: 637

33. Paes EC, van der Mink Molen AB, Muradin MS et al (2013) A systematic review on the outcome of mandibular distraction osteogenesis in infants suffering Robin sequence. Clin Oral Investig 17: 1807

34. Papoff P, Guelfi G, Cicchetti R et al (2013) Outcomes after tonguelip adhesion or mandibular distraction osteogenesis in infants with Pierre Robin sequence and severe airway obstruction. Int J Oral Maxillofac Surg 42:1418

35. Anderson KD, Cole A, Chuo CB et al (2007) Home management of upper airway obstruction in Pierre Robin sequence using a nasopharyngeal airway. Cleft Palate Craniofac J 44:269

36. de Vries IA, Breugem CC, van der Heul AM et al (2014) Prevalence of feeding disorders in children with cleft palateonly: a retrospective study. Clin Oral Investig 18:1507

37. Talma H, Schönbeck Y, Bakker B, Hirasing RA, van Buuren S (2010) Groeidiagrammen 2010: Handleiding bij het meten en wegen van kinderen en het invullen van groeidiagrammen. TNO Kwaliteit van Leven, Leiden, and personal communication

38. Liberati A, Altman DG, Tetzlaff J et al (2009) The PRISMA statement for reporting systematic reviews and meta-analyses of studies that evaluate health care interventions: explanation and elaboration. PLoS Med 6:e1000100

39. Philips B, Ball B, Sackett D (2015) Oxford centre for evidencebased medicine-levels of evidence. Available at: http://www. cebm.net $/ 0=1025$. Accessed january 14 th

40. Abadie V, Morisseau-Durand MP, Beyler C et al (2002) Brainstem dysfunction: a possible neuroembryological pathogenesis of isolated Pierre Robin sequence. Eur J Pediatr 161:275

41. Cruz MJ, Kerschner JE, Beste DJ et al (1999) Pierre Robin sequences: secondary respiratory difficulties and intrinsic feeding abnormalities. Laryngoscope 109:1632

42. Daniel M, Bailey S, Walker K et al (2013) Airway, feeding and growth in infants with Robin sequence and sleep apnoea. Int $\mathrm{J}$ Pediatr Otorhinolaryngol 77:499

43. Evans AK, Rahbar R, Rogers GF et al (2006) Robin sequence: a retrospective review of 115 patients. Int J Pediatr Otorhinolaryngol 70:973

44. Gozu A, Genc B, Palabiyik M et al (2010) Airway management in neonates with Pierre Robin sequence. Turk J Pediatr 52:167

45. Hamdi M, Brutus JP, De Mey A (2004) Clinical experience with the Pierre Robin sequence. Eur J Plast Surg 26:401-405

46. Li HY, Lo LJ, Chen KS et al (2002) Robin sequence: review of treatment modalities for airway obstruction in 110 cases. Int $\mathrm{J}$ Pediatr Otorhinolaryngol 65:45
47. Lidsky ME, Lander TA, Sidman JD (2008) Resolving feeding difficulties with early airway intervention in Pierre Robin Sequence. Laryngoscope 118:120

48. Maas C, Poets CF (2014) Initial treatment and early weight gain of children with Robin Sequence in Germany: a prospective epidemiological study. Arch Dis Child Fetal Neonatal Ed 99:F491

49. Meyer AC, Lidsky ME, Sampson DE et al (2008) Airway interventions in children with Pierre Robin Sequence. Otolaryngol Head Neck Surg 138:782

50. Smith MC, Senders CW (2006) Prognosis of airway obstruction and feeding difficulty in the Robin sequence. Int $\mathrm{J}$ Pediatr Otorhinolaryngol 70:319

51. Stubenitsky BM, Taylor HO, Peters D et al (2010) Predictive value of weight gain and airway obstruction in isolated Robin sequence. Cleft Palate Craniofac J 47:378

52. van den Elzen AP, Semmekrot BA, Bongers EM et al (2001) Diagnosis and treatment of the Pierre Robin sequence: results of a retrospective clinical study and review of the literature. Eur $\mathrm{J}$ Pediatr 160:47

53. van Lieshout MJ, Joosten KF, Hoeve HL et al (2013) Unravelling Robin sequence: Considerations of diagnosis and treatment. Laryngoscope

54. Wagener S, Rayatt SS, Tatman AJ et al (2003) Management of infants with Pierre Robin sequence. Cleft Palate Craniofac J 40:180

55. Prochazkova J, Vinsova J (1995) Craniofacial morphology as a marker of predisposition to isolated cleft palate. J Craniofac Genet Dev Biol 15:162

56. Spriestersbach DC, Dickson DR, Fraser FC et al (1973) Clinical research in cleft lip and cleft palate: the state of the art. Cleft Palate J 10:113

57. Becker M, Svensson H, Kallen B (1998) Birth weight, body length, and cranial circumference in newborns with cleft lip or palate. Cleft Palate Craniofac J 35:255

58. Marques IL, Bettiol H, de Souza L et al (2008) Longitudinal study of the growth of infants with isolated Robin sequence considered being severe cases. Acta Paediatr 97:371

59. Felix-Schollaart B, Hoeksma JB, Prahl-Andersen B (1992) Growth comparison between children with cleft lip and/or palate and controls. Cleft Palate Craniofac J 29:475

60. Wan T, Wang G, Yang Y (2014) The nutrition status of mild form Pierre Robin sequence before cleft palate repair: an analysis of 34 cases. Oral Surg Oral Med Oral Pathol Oral Radiol 118:43

61. Paes EC, van Nunen DPF, Speleman L et al (2015) In press A pragmatic approach to infants with Robin sequence: A retrospective cohort study and presence of a treatment algorithm. Clin Oral Investig

62. Denny A, Amm C (2005) New technique for airway correction in neonates with severe Pierre Robin sequence. J Pediatr 147:97

63. Looby JF, Schendel SA, Lorenz HP et al (2009) Airway analysis: with bilateral distraction of the infant mandible. J Craniomaxillofac Surg 20:1341

64. Olson TP, McMurray JS, Mount DL (2011) Endoscopic changes in the upper airway after mandibular distraction osteogenesis. J Craniomaxillofac Surg 22:105

65. Buchenau W, Wenzel S, Bacher M et al (2016) Functional treatment of airway obstruction and feeding problems in infants with Robin sequence. Arch Dis Child Fetal Neonatal Ed 0:F1-F5

66. Cooper-Brown L, Copeland S, Dailey S et al (2008) Feeding and swallowing dysfunction in genetic syndromes. Dev Disabil Res Rev 14:147

67. Al-Attar H, Shergill AK, Brown NE et al (2011) Percutaneous gastrostomy tubes in children with Pierre Robin sequence: efficacy, maintenance and complications. Pediatr Radiol

68. Al-Samkari HT, Kane AA, Molter DW et al (2010) Neonatal outcomes of Pierre Robin sequence: an institutional experience. Clin Pediatr (Phila) 49:1117 
69. Hoffman W (2003) Outcome of tongue-lip plication in patients with severe Pierre Robin sequence. J Craniomaxillofac Surg 14:602

70. Spring MA, Mount DL (2006) Pediatric feeding disorder and growth decline following mandibular distraction osteogenesis. Plast Reconstr Surg 118:476

71. Evans KN, Sie KC, Hopper RA et al (2011) Robin sequence: from diagnosis to development of an effective management plan. Pediatrics 127:936

72. Denny AD (2004) Distraction osteogenesis in Pierre Robin neonates with airway obstruction. Clin Plast Surg 31:221

73. da Silva AP, Lubianca Neto JF, Santoro PP (2010) Comparison between videofluoroscopy and endoscopic evaluation of swallowing for the diagnosis of dysphagia in children. Otolaryngol Head Neck Surg 143:204

74. Marques IL, Prado-Oliveira R, Leiriao VH et al (2010) Clinical and fiberoptic endoscopic evaluation of swallowing in robin sequence treated with nasopharyngeal intubation: the importance of feeding facilitating techniques. Cleft Palate Craniofac J 47:523

75. Renault F, Flores-Guevara R, Soupre V et al (2000) Neurophysiological brainstem investigations in isolated Pierre Robin sequence. Early Hum Dev 58:141

76. Marques IL, Peres SP, Bettiol H et al (2004) Growth of children with isolated Robin sequence treated by nasopharyngeal intubation: importance of a hypercaloric diet. Cleft Palate Craniofac J 41:53

77. Nassar E, Marques IL, Trindade AS Jr et al (2006) Feedingfacilitating techniques for the nursing infant with Robin sequence. Cleft Palate Craniofac J 43:55
78. Skillman J, Cole A, Slator R (2012) Sodium Supplementation in Neonates With Pierre Robin Sequence Significantly Improves Weight Gain if Urinary Sodium Is Low. Cleft Palate Craniofac J 49:39

79. Speltz ML, Armsden GC, Clarren SS (1990) Effects of craniofacial birth defects on maternal functioning postinfancy. J Pediatr Psychol 15:177

80. Endriga M, Speltz M, Maris C et al (1998) Feeding and attachment in infants with and without orofacial clefts. Infant Behavior and Development 21:699-712

81. Arvedson J, Brodsky L (2002) Pediatric swallowing and feeding: assessment and managment. Albany, NY, Singular Thomson Learning

82. Hulst JM, van Goudoever JB, Zimmermann LJ et al (2004) The effect of cumulative energy and protein deficiency on anthropometric parameters in a pediatric ICU population. Clin Nutr 23:1381

83. Mitchell IM, Logan RW, Pollock JC et al (1995) Nutritional status of children with congenital heart disease. Br Heart J 73:277

84. Kochel J, Meyer-Marcotty P, Wirbelauer J et al (2011) Treatment modalities of infants with upper airway obstruction-review of the literature and presentation of novel orthopedic appliances. Cleft Palate Craniofac J 48:44

85. Buchenau W, Urschitz MS, Sautermeister J et al (2007) A randomized clinical trial of a new orthodontic appliance to improve upper airway obstruction in infants with Pierre Robin sequence. J Pediatr $151: 145$

86. Miller CK (2011) Feeding issues and interventions in infants and children with clefts and craniofacial syndromes. Semin Speech Lang 32:115

87. Kallen K (1997) Maternal smoking and orofacial clefts. Cleft Palate Craniofac J 34:11 